Alejandro George Cruz Los símbolos, la interacción y la estrategia. Una propuesta de abordaje teórico-comunicológico a los fenómenos sociales: el culto a la Santa Muerte como un caso aproximación. Revista Xihmai XIV (27), 35-62, enero-junio 2019

\title{
Xíhmai
}

Universidad La Salle Pachuca

xihmai@lasallep.edu.mx

Teléfono: 01(771) 7170213 ext. 1406

Fax: 01(771) 7170309

ISSN (versión impresa):1870-6703

México

Alejandro George Cruz

LOS SÍMBOLOS, LA INTERACCIÓN Y LA ESTRATEGIA. UNA PROPUESTA DE ABORDAJE TEÓRICO-COMUNICOLÓGICO A LOS FENÓMENOS SOCIALES:

EL CULTO A LA SANTA MUERTE COMO UN CASO APROXIMACIÓN.

THE SIMBOLS, THE INTERACTION AND THE STRATEGY. A PROPOSAL OF THEORETICAL-COMMUNICOLOGIST APPROACH TO THE SOCIAL PHENOMENA: THE SANTA MUERTE'S CULT AS A CASE OF APPROXIMATION.

Xihmai, año 2019/vol. XIV, número 27

Universidad La Salle Pachuca

pp. 35-62 
Alejandro George Cruz

Los símbolos, la interacción y la estrategia. Una propuesta de abordaje teórico-comunicológico a los fenómenos sociales: el culto a la Santa Muerte como un caso aproximación. Revista Xihmai XIV (27), 35-62, enero-junio 2019

Xihmai 36 
Los símbolos, la interacción y la estrategia. Una propuesta de abordaje teórico-comunicológico a los fenómenos sociales: el culto a la Santa Muerte como un caso aproximación.

Revista Xihmai XIV (27), 35-62, enero-junio 2019

\section{LOS SÍMBOLOS, LA INTERACCIÓN Y LA ESTRATEGIA. UNA PROPUESTA DE ABORDAJE TEÓRICO-COMUNICOLÓGICO A LOS FENÓMENOS SOCIALES: EL CULTO A LA SANTA MUERTE COMO UN CASO APROXIMACIÓN.}

THE SIMBOLS, THE INTERACTION AND THE STRATEGY. A PROPOSAL OF THEORETICAL-COMMUNICOLOGIST APPROACH TO THE SOCIAL PHENOMENA: THE SANTA MUERTE'S CULT AS A CASE OF APPROXIMATION.

Alejandro George Cruz

Maestro en Comunicación y Política. Egresado del Doctorado en Ciencias Sociales con orientación en comunicación y política.

Profesor investigador de tiempo completo en la Facultad de Comunicación de la Benemérita Universidad

Autónoma de Puebla. alejandro.george@correo.buap.mx

\section{Resumen}

Una revisión somera sobre los estudios que se han publicado sobre el fenómeno de la "veneración a la Santa Muerte" muestra que ha sido primordialmente abordado desde miradas antropológicas y sociológicas, lo cual tiene mucho sentido si consideramos que las prácticas y sistemas simbólicos que envuelven estas manifestaciones son casi naturalmente el ámbito de estudio de las disciplinas anteriormente señaladas; sin embargo, a través de este escrito, pretendemos abordar el fenómeno desde otra perspectiva, que podría antojarse poco relacionada con los temas de la religión, las prácticas rituales y los universos simbólicos: la comunicación. En este artículo se presenta una disertación teórica sobre los símbolos, la interacción y la estrategia como dimensiones comunicológicas de aproximación a los fenómenos sociales y se intenta utilizarlas como áreas de posible abordaje del fenómeno del culto a la Santa Muerte.

Palabras clave: Símbolos, interacción, estrategia, comunicación, análisis comunicológico. 


\section{Abstract}

A brief review of the studies that have been published about the phenomenon of "Santa Muerte" worship, makes notorious that it has been primarily approached from anthropological and sociological perspectives, which makes a lot of sense if we consider that the symbolic systems and practices that surround these manifestations are almost naturally the scope of study of the disciplines previously indicated, however, through this paper, we intend to approach the phenomenon from another perspective, which could seem unconnected with the topics of religion, ritual practices and the symbolic universes: Communication. This article presents a theoretical dissertation on symbols, interaction and strategy as communicological dimensions of approach to social phenomena and attempts to use them as areas of possible analysis of the phenomenon of the cult of Santa Muerte.

Keywords: Symbols, interaction, strategy, communication, communication analysis.

\section{La "Santa Muerte" como objeto de estudio}

El interés por este tema surgió de un curso que impartí en mayo de 2013, sobre análisis de datos de investigación en la licenciatura en Comunicación de la Benemérita Universidad Autónoma de Puebla. Durante este curso, los propios estudiantes comenzaron a referir una diversidad de temáticas sobre las que versaba su interés de indagar la realidad social. Al momento de plantear un trabajo en conjunto, en el que los estudiantes incursionarían en un campo de investigación para describirlo, el tema del culto a la Santa Muerte se perfiló como uno de los favoritos por dos razones: Primero, se trata de un tema que por su naturaleza está envuelto en el misterio propio del desconocimiento de las prácticas y creencias de quienes son devotos; segundo, la propuesta misma consiste en afrontar un tema de esta naturaleza con una mirada desde la comunicación.

Al plantear el objeto de estudio, se realizó, en ese entonces, un estado de la cuestión que permitiera establecer desde dónde se ha estudiado el fenómeno, con qué resultados y con qué posibilidades de abordarlo como un tema de comunicación. Si bien el trabajo de entonces resultó en una suerte de collage

Xihmai 38 


\section{Alejandro George Cruz \\ Los símbolos, la interacción y la estrategia. Una propuesta de abordaje teórico-comunicológico a los fenómenos sociales: el culto a la Santa Muerte como un caso aproximación. \\ Revista Xihmai XIV (27), 35-62, enero-junio 2019}

de perspectivas que sólo establecieron una base para abordar el fenómeno, hoy se puede plantear una perspectiva diferente. El tema de la Santa Muerte se ha investigado de forma ingente desde básicamente dos disciplinas: la antropología y la sociología, las dimensiones que abordaremos más adelante también se han considerado como objeto de estudio de las disciplinas anteriormente mencionadas. A continuación, nos referiremos a algunos artículos publicados que fueron seleccionados debido a que su título y tópico sugerían la posibilidad de relacionarse con los símbolos, la interacción o la estrategia.

En el artículo "Santa Muerte entre los malditos. Culto a la santa muerte en el siglo XXI", Felipe Gaytán Alcántara (2008) reflexiona que este culto se ha extendido en el imaginario social de distintas regiones de América Latina, que no se trata de un fenómeno localizado o restringido a un grupo social, ya que el culto es transversal a distintos niveles socioeconómicos. Destaca que el culto trasciende su misterio y contenidos esotéricos para convertirse en un símbolo por medio del cual se representa la fragilidad de la vida, por lo que los símbolos y rituales que rodean el culto son una forma de reivindicar la vida como una tragedia y la muerte como un destino que no se puede evitar. En este artículo se da cuenta del poder representacional que tiene el culto para significar incertidumbres propias de la vida y manejarlas simbólicamente a través de rituales que proveen certidumbre ante los miedos y angustias.

Por su parte, Katia Perdigón (2015), en el artículo "La indumentaria para la Santa Muerte", analiza algo más concreto como el cambio de las vestiduras que atavían las imágenes de la Santa Muerte. Explica que algunos elementos, como el modelo y el color de las vestimentas, se relacionan con conceptos como el amor, la prosperidad, la salud, etc. No se trata simplemente de una prenda, es un símbolo importante para los devotos, ya que, si bien no todos los feligreses participan en la elección de las mismas, éstas atribuyen a la imagen un medio por el que sus devotos se vinculan con ella y por medio de la cual, desde el punto de vista de los creyentes, aquella se complace de vivir y convivir con ellos. Este articulo evidencia que los símbolos son un elemento importante que se integra en la vida cotidiana y por medio de los cuales se generan identidades. 


\section{Alejandro George Cruz \\ Los símbolos, la interacción y la estrategia. Una propuesta de abordaje teórico-comunicológico a los fenómenos sociales: el culto a la Santa Muerte como un caso aproximación. \\ Revista Xihmai XIV (27), 35-62, enero-junio 2019}

En "Historia y actualidad de la Santa Muerte", Claudia Reyes Ruiz (2011) comenta que una característica del culto estriba en que no existen mediadores o representantes que intervengan en él, por lo que la idea de la veneración de la muerte se encuentra al alcance de todos. Esto ha favorecido que en los procesos de enunciación de apego a la imagen se presenten expresiones como: "Flaquita", "Madrina", "Hermana Blanca", "Comadre", etc., lo que devela una familiaridad con la imagen, provocando procesos rituales diversos que se explican por sí mismos. En este artículo podemos perfilar que los símbolos se utilizan en la vida cotidiana de diversas maneras y con diversos propósitos, pero específicamente enmarcados en contextos de significación singulares, generando procesos de interacción significativos para los creyentes o devotos a partir de los cuales se generan narrativas de los procesos y ritos en la vida cotidiana que adquieren sentido, especialmente en aquellos momentos en que se presentan las "necesidades terrenales".

Los artículos anteriores nos permiten suponer que los conceptos de imaginario social, símbolo y percepción se han utilizado para referirse a elementos constitutivos de las prácticas y rituales sui generis relacionados con la Santa Muerte. Por lo tanto, cabe preguntarse ¿Qué podrían tener en común estos conceptos, plasmados en los trabajos anteriormente referidos, con la comunicación?

\section{La comunicación como un fenómeno articulador de lo social}

Se podría considerar que estaría de más que este trabajo en torno a la "comunicación" inicie con un esclarecimiento de lo que se entiende con este término y no lo es si consideramos que el primer desafío que enfrentan quienes se dedican al estudio del campo de la comunicación, es el problema de su definición. El reto no es menor si se toma en cuenta que diversos investigadores en ciencias sociales concuerdan con el hecho de que se trata de un fenómeno de grandes proporciones, de naturaleza eminentemente social y por lo tanto imposible de asir en una escueta definición (Roda y Beltrán, 1988; Payrató, 1998; Martino, 2001).

A lo anterior podríamos añadir que la carga semántica del término, tal y como se usa en el lenguaje cotidiano, incluye un vasto número de acepciones, lo que hace inviable una aproximación al campo de la comunicación sin proceder

Xihmai 40 
Los símbolos, la interacción y la estrategia. Una propuesta de abordaje teórico-comunicológico a los fenómenos sociales: el culto a la Santa Muerte como un caso aproximación. Revista Xihmai XIV (27), 35-62, enero-junio 2019

antes a un análisis crítico de su significado y de lo que se pretende esclarecer con dicho análisis. Por lo tanto, no es infructuoso proponer un concepto de comunicación, así como las razones del empeño en trabajar desde ese punto de vista. Cabe aclarar que no se pretender proponer una definición del término, sino matizar una dimensión del ingente campo con el fin de resaltar aquello que sea útil heurística y analíticamente a los fines de esta propuesta.

En términos más o menos generales se ha entendido a la comunicación como una correspondencia entre elementos que guardan una cierta afinidad, un proceso entre seres o entes, ya sean orgánicos o inorgánicos, que involucra grosso modo el sentido de "transmisión" (Martino, 2001). Este concepto muy general permitiría su aplicación a casi cualquier clase de relación y pierde especificidad. Sin embargo, se pueden subrayar dos ideas que resultan útiles para avanzar en nuestra propuesta: enlace y transferencia.

El enlace implica la existencia de por lo menos dos elementos separados que se encuentran situados en un espacio y que se relacionan entre sí, ya sea física o socialmente; la transferencia envuelve la emisión y recepción de una magnitud, que en el sentido físico se refiere a una intensidad de intercambio entre entes y en el sentido social a la transmisión de información entre individuos. Lo anterior nos permite descartar, de nuestro interés, las acepciones que se refieren a los objetos inanimados y sugerir que la comunicación no es, en el sentido que nos interesa, una objetivación mesurable o cuantificable, ni siquiera se trata exclusivamente de un proceso relacional entre magnitudes o entes en virtud de lo que comparten o tienen en común, aludiendo a otra acepción basada en la raíz etimológica del término (Roda y Beltrán, 1988).

Así, la comunicación, desde donde aquí se aborda, es una esencia del hombre, una manera del ser humano que implica el reconocimiento de ciertas capacidades que posee como la percepción, la memoria, la reflexión, el lenguaje, etcétera ${ }^{1}$. Se trata de un ser simbólico que en su dependencia con otro

\footnotetext{
${ }^{1}$ Se encuentra fuera del propósito de este escrito disertar sobre los factores etiológicos que hacen posible esta manera de ser del hombre y que sin duda también pueden ser reconocidos como capacidades en otras formas de vida; sin embargo, se puede afirmar que existe una diferencia cualitativa que marca el contraste efectivo entre la comunicación como un fenómeno exclusivamente humano y las capacidades comunicativas de los demás seres vivos, a saber: el lenguaje articulado.
} 
Los símbolos, la interacción y la estrategia. Una propuesta de abordaje teórico-comunicológico a los fenómenos sociales: el culto a la Santa Muerte como un caso aproximación.

Revista Xihmai XIV (27), 35-62, enero-junio 2019

semejante no está determinado solamente por el espacio físico-temporal inherente a la relación que establece para su supervivencia, sino que construye ese espacio y lo transforma en entorno social, ubicándose en él como sujeto. (Schütz, 1993).

Así, planteamos una premisa inicial que propone entender la comunicación como el proceso social básico por medio del cual los hombres se construyen y se conservan como seres sociales (Hartley y Hartley, 1986). En este argumento, la comunicación es vital para el hombre tanto individual como colectivamente, como afirma López (1997):

Si se parte de un análisis antropológico e histórico, la comunicación comenzaría a revelársenos como un principio de relación humana implícita en el proceso mismo de la estructuración de cualquier forma de vida colectiva, independientemente del grado particular de desarrollo tecnológico, es decir, desde una posición filosófica, la comunicación -el hacer y el ser en común- deviene principio inalienable tanto del individuo como del género humano en su totalidad (1997, p. 9).

Si bien es cierto que aún desde esta propuesta la comunicación no puede escindirse del todo de su sentido más lato, ya expuesto, concretamente el ser simbólico de los sujetos adquiere fuerza a través de la evocación, lo que permite emular la conciencia, la mente, los pensamientos de otros, participando y haciendo común las sensaciones, deseos y afectos de los demás, es decir, los significados que dan sentido a la vida. Por lo tanto, la comunicación, como principio de relación, se revela como un ámbito eminentemente simbólico.

Este primer argumento no estaría completo sin resaltar el hecho de que aun cuando lo simbólico es fundamental, el principio de relación del que hemos hablado se hace efectivo a través de la interacción, es decir el ámbito de influencia recíproca que se gesta entre los sujetos participantes en cualquier situación social, por el que construyen y proyectan su subjetividad y visiones del mundo, creando sus expectativas y orientando sus acciones en el mundo de la vida.

\section{Dimensión simbólica de la comunicación}

Se ha planteado lo simbólico y la interacción como dimensiones esenciales del fenómeno de comunicación humana, por lo tanto, es necesario puntualizar Xihmai 42 


\section{Alejandro George Cruz \\ Los símbolos, la interacción y la estrategia. Una propuesta de abordaje teórico-comunicológico a los fenómenos sociales: el culto a la Santa Muerte como un caso aproximación. Revista Xihmai XIV (27), 35-62, enero-junio 2019}

estas nociones para dejar en claro qué se entiende por éstas y cómo ayudan a abordar el fenómeno de la "devoción a la Santa Muerte".

Se entiende por dimensión simbólica el ámbito de atribución de significado a cualquier cosa, ya sea un objeto o acción. Esta atribución es posible por medio de la facultad humana de la significación, que hace viable la aprehensión del universo cognoscible a través de los signos.

El tema de los signos y la significación se ha planteado, a lo largo de la historia, como un problema filosófico del lenguaje que a su vez participa de ciertas vertientes de la filosofía del conocimiento. Los filósofos, incluyendo a los clásicos Platón y Aristóteles, generalmente han utilizado sus ideas en torno al lenguaje para aproximarse a reflexiones de carácter epistemológico y ontológico. Por ejemplo, el último aborda la cuestión del lenguaje, pero centra sus argumentos en el papel que este desempeña en la lógica. De principio, las palabras se consideran como una convención consubstancial a cada lengua, mientras que la significación, en cuanto proceso mental y referencial a "las afecciones del alma", se considera universal. No obstante, las palabras en sí mismas no revelan ni verdad ni falsedad, para ello se requiere que haya atribución, la cual sólo es posible a través de la función verbal, lo que evidencia la necesidad de una sintaxis que permita la construcción preposicional de la lógica.

En la modernidad, el lenguaje también se plantea como un problema de significación y comunicación en estrecha relación con el conocimiento en los trabajos de Locke (1956) y Leibniz (1977), coincidiendo ambos en que se trata de una dimensión social del hombre (Blasco et al., 1999).

Más recientemente, a principios del siglo XX, la filosofía analítica ${ }^{2}$ y específicamente en voz de Michael Dummet (1973), esboza la posibilidad de que el lenguaje y su lugar en la reflexión filosófica no se trate sólo de un instrumento analítico arbitrario sino que, efectivamente, "los grandes

${ }^{2}$ Si bien la filosofía analítica no considera que exista una primacía del lenguaje sobre el pensamiento, postula una tesis metodológica: dar prioridad al carácter filosófico del estudio del lenguaje y de los conceptos tal y como se expresan en el lenguaje, sobre el estudio de los pensamientos. Algunos de los grandes representantes de la filosofía analítica del lenguaje son: Frege, Russell, Wittgenstein, Quine, Sellars, y Davidson.

Xihmai 43 
Los símbolos, la interacción y la estrategia. Una propuesta de abordaje teórico-comunicológico a los fenómenos sociales: el culto a la Santa Muerte como un caso aproximación. Revista Xihmai XIV (27), 35-62, enero-junio 2019

problemas filosóficos sean planteados como problemas lingüísticos" (GarcíaCarpintero, 1996, p. XVII). Por ejemplo: Ludwig Wittgenstein había propuesto, en el Tractatus logico-philosophicus, que "dar la esencia de la proposición significa dar la esencia de toda descripción; o sea, la esencia del mundo" (Wittgenstein, 1987, p. 68), es decir, que las oraciones proposicionales poseen la capacidad de representar un estado de cosas posible y, por lo tanto, son signos que tienen la función de constatar la veracidad o falsedad de ese estado posible.

Así, se puede establecer que es innegable que desde la filosofía del lenguaje se han sentado algunas de las bases conceptuales de lo que podríamos denominar "teoría de la significación", sin embargo, no es sino hasta finales del siglo XIX que se acomete un estudio sistemático de esta, desde dos campos diferentes, pero igualmente interesados por el lenguaje: la semiótica ${ }^{3}$ de Charles Sanders Peirce y la lingüística de Ferdinand de Saussure.

Sin perder de vista que la reflexión filosófica no puede deslindarse del lenguaje, más concretamente de proponer por vía del lenguaje la emergencia del conocimiento ${ }^{4}$, no resultaría extraño que Locke ya hubiera expresado que el avance de la ciencia no sería posible sin el estudio de los instrumentos de los que se sirve: los signos. Sin embargo, fue Charles Sanders Peirce quien retomó el reto de Locke y sentó las bases de una "doctrina formal de los signos" (Peirce, 1986, p. 21) por medio de la cual la ciencia pudiera conseguir una representación verdadera de la realidad (Blasco et al., p. 1999). Aunque este fue el propósito original de Peirce, su teoría es lo suficientemente amplia y por lo tanto aplicable a todo tipo de representación en general, ya sea esta de carácter científico, filosófico, religioso, estético, etcétera.

Por lo general, se considera a Peirce como el fundador de la "semiótica", aunque él mismo no propone este término, sino que lo retoma del pensamiento de Locke. La importancia del signo para Peirce es fundamental porque una

\footnotetext{
${ }^{3}$ El término «semiótica» suele usarse con frecuencia como sinónimo de «semiología», la mayoría de las veces remiten a dos perspectivas bien definidas, correspondiendo la semiótica a las propuestas teóricas de Peirce y la semiología a las de Saussure.

${ }^{4}$ Aunque la filosofía del lenguaje no es propiamente una lingüística en el sentido contemporáneo, se cuestionaba por los signos lingüísticos como entidades epistémicas insertadas en códigos, que en la lingüística moderna, a partir de Saussure, se referirían a las lenguas.
}

Xihmai 44 
Los símbolos, la interacción y la estrategia. Una propuesta de abordaje teórico-comunicológico a los fenómenos sociales: el culto a la Santa Muerte como un caso aproximación. Revista Xihmai XIV (27), 35-62, enero-junio 2019

teoría de la significación le permitiría ir contra la corriente "cartesiana" en la filosofía y la ciencia, la cual consideraba que el conocimiento viene de la "duda universal" primigenia que para Peirce sería un autoengaño.

[...] no podemos comenzar con la duda completa. Debemos comenzar con todos los prejuicios que tenemos realmente [...] no existe una cognición absolutamente primera de cualquier objeto, sino que la cognición surge mediante un proceso continuo. Por ende, debemos comenzar con un proceso de cognición... (Peirce, 1987, pp. 60-61).

Esta argumentación tiene su fundamento en el razonamiento de que "no tenemos ninguna facultad de pensar sin signos" (1987, p. 60) y por lo tanto su teoría busca destacar el carácter ontológico de los signos, así como su cualidad lógica en los procesos cognitivos de naturaleza epistémica.

Peirce definió el signo como "algo que, para alguien, representa o se refiere a algo en algún aspecto o carácter" (1986, p. 22). Esta cualidad de representación o de referencia (de estar en lugar de algo o alguien representándolo) es posible mediante un proceso por medio del cual ese algo (objeto), por la razón que sea, se constituye en representamen (un primer signo) de sí mismo o algo más y crea un signo equivalente (interpretante del primer signo) ${ }^{5}$ pero más desarrollado en la mente de aquél a quien se dirige dicho signo. Este es el proceso que Peirce denominó proceso semiótico. Se trata de un proceso infinito pues, a su vez, el interpretante se convierte en objeto constituyente de otro representamen que tiene un interpretante como equivalente, y así ad infinitud (Peirce, 1986).

Para Peirce los signos tienen una cualidad que nos permite inferir y reconocer los significados que les son atribuidos; así, los signos son operaciones lógicas por medio de las cuales pensamos sobre nosotros mismos y sobre nuestro mundo físico y social. Estos procesos mentales lógicos son una experiencia que se realiza en todo momento en la vida, lo que se denomina semiosis, y la semiótica será la teoría de esa experiencia (Vitale, 2002). La concepción

\footnotetext{
${ }^{5}$ Aunque cualquier cosa puede ser constituida como signo, las cosas no significan nada por sí mismas. Sólo mediante el proceso semiótico, una operación mental de reconocimiento y conocimiento, es posible atribuir significado a las cosas. Las cosas pueden ser signos de sí mismas pero no pueden representar o significar nada más si no se les atribuye dicha propiedad a través del proceso semiótico (Peirce, 1986).
} 


\section{Alejandro George Cruz \\ Los símbolos, la interacción y la estrategia. Una propuesta de abordaje teórico-comunicológico a los fenómenos sociales: el culto a la Santa Muerte como un caso aproximación. Revista Xihmai XIV (27), 35-62, enero-junio 2019}

peirciana del signo nos ayuda a comprender que la significación es una operación lógica del pensamiento que genera un proceso de conocimiento.

Por su parte, Ferdinand de Saussure (1998) define el signo desde la lingüística, refiriéndose al sistema de signos que constituye la lengua, un sistema reglamentado de significación $\mathrm{y}$, por lo tanto, "modelo" de otras formas de significación:

El signo lingüístico no une una cosa y un nombre, sino un concepto y una imagen acústica. Esta última no es el sonido material, cosa puramente física, sino su huella psíquica, la representación que de él nos da el testimonio de nuestros sentidos [...] el carácter psíquico de nuestras imágenes acústicas aparece claramente cuando observamos nuestra lengua materna. Sin mover los labios ni la lengua, podemos hablarnos a nosotros mismos [...] el signo lingüístico es por tanto una entidad psíquica de dos caras. Estos dos elementos están íntimamente unidos y se reclaman recíprocamente [...] llamamos signo a la combinación del concepto y de la imagen acústica [...] nosotros proponemos conservar la palabra signo para designar la totalidad y remplazar concepto e imagen acústica respectivamente por significado y significante (1998, pp. 102-104).

A modo de recapitulación sobre estas dos perspectivas y su aportación en la comprensión de la dimensión simbólica de la comunicación, se puede afirmar que la semiótica permite comprender el papel que juegan los signos y la significación en el proceso personal de conocimiento y aprendizaje, así como en la conformación de nuestro entorno social, a través del pensamiento lógico que opera en los individuos y hace posible reconocer los significados atribuidos socialmente a los objetos y acciones que se presentan en la vida cotidiana.

La semiología, por su parte, devela una dimensión del signo que no se encuentra asociada directamente con la persona que reconoce los signos de forma lógica, por el contrario, resalta la participación cognoscente de otros individuos en la atribución de tal o cual significado. Además, centra su atención en lo que sucede en el entorno, lo que permite el establecimiento de sistemas de significación (como la lengua) que se convencionalizan y permiten poner en común ideas, valores, creencias, reglas de convivencia, que se refieren a la comunicación de los significados, los cuales son consensuados, compartidos, aprendidos y reconocidos (Roda y Beltrán, 1988).

Xihmai 46 


\section{Alejandro George Cruz \\ Los símbolos, la interacción y la estrategia. Una propuesta de abordaje teórico-comunicológico a los fenómenos sociales: el culto a la Santa Muerte como un caso aproximación. \\ Revista Xihmai XIV (27), 35-62, enero-junio 2019}

En conclusión, en todo fenómeno comunicativo la significación juega un papel importante, ya que ésta es de carácter subjetivo, es decir, los sujetos que intervienen en una situación social atribuyen significados a lo que ocurre a su alrededor (Salomon, 1981). Es fundamental que los integrantes de una sociedad consideren significativo un hecho, un acto, un evento, porque de esta forma se puede entender que las experiencias sensoriales y cognitivas de los sujetos participantes convierten las acciones propias y de los demás en "mensajes".

El modelo de significación se establece por medio de una relación instituida socialmente, objetivada por conveniencia en un código (Eco, 1988) entre objetos significantes (sensoriales) y los significados (cognitivos). La dimensión simbólica nos remite por lo tanto a la dimensión social, ya que los mensajes se construyen socialmente por medio de los sistemas de significación y sus reglas, es decir, de acuerdo con convenciones. Al tratarse de atribuciones, se ponen a disposición de los demás dentro de un escenario común con la posibilidad de crear nuevos significados. Por lo tanto, los mensajes no son formas rígidas de significación que sólo se transmiten en un proceso cerrado, son complejas relaciones de atribución significativa de carácter eminentemente social y abierto.

\section{Dimensión interaccional de la comunicación}

Como se ha afirmado con anterioridad, la comunicación es un proceso social, dinámico, articulador, organizador y regulador de la experiencia humana, vinculada al fenómeno de compartir, de poner significados en común. Esta vinculación y participación simbólica se realiza a través del lenguaje y se manifiesta en los actos, hechos y acciones que se llevan a cabo en contextos sociales concretos, escenarios de comunicación en los que se comparten, intercambian, juegan y negocian significados sobre la vida cotidiana entre dos o más individuos (O’Sullivan et al., p. 1997).

Por lo anterior, se denomina dimensión interaccional al ámbito de influencia recíproca que se gesta entre los individuos participantes en cualquier situación comunicativa específica. Por medio de ésta se adecuan sus conversaciones, acciones y expectativas en relación con el contexto y los escenarios de 
Los símbolos, la interacción y la estrategia. Una propuesta de abordaje teórico-comunicológico a los fenómenos sociales: el culto a la Santa Muerte como un caso aproximación.

Revista Xihmai XIV (27), 35-62, enero-junio 2019

comunicación; esto permite el intercambio y la negociación de los significados sociales.

Es en y por la interacción, que la comunicación como proceso social hace posible la organización de las comunidades y de la sociedad. En el proceso de comunicación los sujetos se forjan entre sí como seres sociales junto con sus modelos de comprensión del mundo, interactuando desde los lugares que ocupan socialmente para la construcción de sentido.

Cabe aclarar que si bien la noción de interacción, desde cierto punto de vista como el conductismo, remite a la idea de una mutua afectación sobre los comportamientos y las acciones de individuos en situaciones de presencia física simultánea, como en el caso del conductismo radical de Watson (1972 [1924]) o el conductismo social de Mead (1972 [1924]), la interacción desde el punto de vista de la comunicación implica mucho más.

Desde la perspectiva que aquí se propone, la interacción no se refiere a una asunción de acciones y reacciones en la conducta, como respuesta a un estímulo externo o a cierta información, sino a una influencia dialógica, recíproca, de carácter social basada en la significación, que implica reglas, normas y dinámicas compartidas. Vista de esta manera, la interacción es una situación sui generis en que se produce el intercambio comunicativo y que crea una situación social completa en sí misma; se trata de un fenómeno social contextualizado.

Esta noción de interacción se fundamenta en dos corrientes de pensamiento que se centran en el análisis, tanto de los aspectos sociales como psicológicos, de los intercambios comunicativos: la sociología fenomenológica y la psicología social. Aquí no se pretende abarcar el extenso campo de estas disciplinas, sino señalar aquellos aspectos en han destacado la interacción como el nudo articulador entre lo social y lo individual.

La sociología fenomenológica tiene sus bases conceptuales en la filosofía fenomenológica de Edmund Husserl (1954) y el método de la sociología comprensiva de Max Weber (1984 [1922]).

Xihmai 48 


\section{Alejandro George Cruz \\ Los símbolos, la interacción y la estrategia. Una propuesta de abordaje teórico-comunicológico a los fenómenos sociales: el culto a la Santa Muerte como un caso aproximación. Revista Xihmai XIV (27), 35-62, enero-junio 2019}

La fenomenología es un movimiento filosófico que inició a finales del siglo XIX y principios del siglo XX que busca instaurar a la filosofía como una ciencia rigurosa, libre de dogmas y especulaciones a través de un método de reducción reflexiva ${ }^{6}$ que permita una aproximación a las cosas del mundo como fenómenos puros de la conciencia. Por su parte, la sociología de Weber da cuenta del proceso de evolución social, político y cultural de la humanidad, centrando su atención en la acción humana como dato de interpretación científica.

Así, el interés de la sociología fenomenológica se centra en las instancias de aproximación al conocimiento de lo cotidiano por parte de los seres sociales, sugiriendo que es en el transcurso de la vida, en el aquí y en el ahora, donde es posible identificar elementos de significación que describen y construyen lo real a través de las acciones sociales.

El principal representante de esta corriente sociológica es el austriaco Alfred Schütz, que retoma la noción de intersubjetividad ${ }^{7}$ de Husserl y lo aplica en un sentido amplio para referirse a la naturaleza social del conocimiento que se tiene sobre el mundo. Desde su perspectiva, los individuos se encuentran inscritos en el mundo social, real, del que saben que son parte y sobre el que conocen por experiencia personal, pero también sobre el que conocen de forma intersubjetiva a través del lenguaje y la cultura que comparten. De este universo de conocimiento compartido extraen los significados, a manera de herramientas simbólicas, que utilizan en la construcción e interpretación de sus sistemas sociales (Schütz, 1993).

\footnotetext{
${ }^{6}$ La reducción reflexiva o epojé es el procedimiento intelectual que consiste en poner entre paréntesis ciertos juicios, ciertos conocimientos para lograr una especie de contacto ingenuo y prerreflexivo con el mundo, con el fin de lograr trascender todo significado cultural y científico y volver a aprehender las cosas en su esencia (Husserl, 1954).

${ }^{7}$ La intersubjetividad en Husserl se basa y se refiere a su noción de reducción reflexiva o método fenomenológico por medio del cual cada sujeto se proyecta como un Yo trascendental que aprehende su mundo de vida a través de los fenómenos puros, lo que Husserl denomina "mónada". La existencia de otros Yo trascendentales implica una comunidad de "mónadas" que aprehenden su mundo de vida de forma idéntica. La intersubjetividad sería la constitución del mundo objetivo a través de la comunidad "intermonadológica" adoptando la perspectiva mundana de los otros Yo trascendentales (Husserl, 1942).
} 


\section{Alejandro George Cruz \\ Los símbolos, la interacción y la estrategia. Una propuesta de abordaje teórico-comunicológico a los fenómenos sociales: el culto a la Santa Muerte como un caso aproximación. Revista Xihmai XIV (27), 35-62, enero-junio 2019}

En la misma tendencia, Peter Berger y Thomas Luckman (2001), discípulos de Schütz, exponen su entendimiento de la sociedad en términos de una construcción. Para ellos, la sociedad se genera en el mundo de la vida cotidiana, la cual se da como una realidad establecida; es un mundo que se origina en el pensamiento y las acciones de los miembros de una comunidad y que está sustentado como una realidad por estos. En otras palabras, la sociedad se genera como si se tratara de una imagen del mundo, orientadora de la acción. La vida cotidiana implica un mundo ordenado mediante significados compartidos por la comunidad.

Su propuesta fenomenológica tiene como objetivo principal la recuperación de las construcciones sociales de la realidad. Incorporan la subjetividad como un dato pertinente en el análisis de la vida cotidiana. La subjetividad se comprende como un fenómeno que pone de manifiesto el universo de significaciones construido colectivamente a partir de la interacción, es decir, el encuentro entre sujetos que va constituyendo el mundo en el enfrentamiento de perspectivas.

Vivo en el mundo del sentido común de la vida cotidiana equipado con cuerpos específicos de conocimiento. Más aún: sé que los otros comparten al menos parcialmente ese conocimiento, y ellos saben que yo lo sé. Mi interacción con los otros en la vida cotidiana resulta, pues, afectada constantemente por nuestra participación común en ese acopio social de conocimiento que está a nuestro alcance $(2001,58)$.

Tanto en Schütz, como en Berger y Luckmann, la interacción aparece como un elemento de análisis importante que implica hablar de la relación entre el yo y el otro, pero no desde la óptica antropológica de las identidades, sino como punto de partida para la construcción social de la realidad. Como afirma Schütz:

Al vivir en el mundo, vivimos como otros y para otros, y orientamos nuestras vidas hacia ellos. Al vivenciarlos como otros, como contemporáneos y congéneres, como predecesores y sucesores, al unirnos con ellos en la actividad y el trabajo común influyendo sobre ellos y recibiendo a nuestra vez su influencia, al hacer todas estas cosas, comprendemos la conducta de los otros y suponemos que ellos comprenden la nuestra (1979, p. 39).

Xihmai 50 


\section{Alejandro George Cruz \\ Los símbolos, la interacción y la estrategia. Una propuesta de abordaje teórico-comunicológico a los fenómenos sociales: el culto a la Santa Muerte como un caso aproximación. \\ Revista Xihmai XIV (27), 35-62, enero-junio 2019}

De acuerdo con Rizo (2005), la interacción constituye la forma de relación por excelencia entre sujetos; el lenguaje, como principal forma de comunicación, participa en este proceso en el que se construyen los significados del mundo a través de los diálogos intersubjetivos. Por lo tanto, la interpretación de lo social tiene como telón de fondo las influencias que las acciones y las conversaciones de las personas tienen en los demás, pero al mismo tiempo sobre sí mismos.

A manera de recapitulación, se podría afirmar que el aporte de la sociología fenomenológica al entendimiento y formulación de la dimensión interaccional de la comunicación estriba en que su postulado sobre la construcción significativa del mundo social evidencia la necesidad del consenso y diálogo intersubjetivo que sólo es posible a través del encuentro entre individuos en situaciones comunicativas, es decir, en interacción.

En el caso de la psicología social, disciplina cuyos antecedentes también se remontan a finales del siglo XIX y la primera mitad del siglo XX, su interés se centra en comprender la forma en que los pensamientos, los sentimientos y la conducta de los individuos están influidos por la presencia actual, imaginada o implícita de los demás (Allport, 1968). Dado que los seres humanos vivimos en sociedad y no aisladamente, la interacción es una constante constitutiva de nuestra realidad, la psicología social intenta destacar el proceso de relación entre el ámbito individual y social de la realidad. Para establecer las aportaciones específicas de la psicología social en la comprensión de la dimensión interaccional de la comunicación, primero esbozaremos un espacio conceptual de la misma.

La psicología social aborda una variedad de temas relacionados con la influencia social y la interacción, con un especial énfasis en la percepción, la cognición social, las actitudes, la persuasión, la socialización, la personalidad, las representaciones sociales, etcétera. Este ámbito de conocimiento busca de manera concreta dilucidar la relación entre el individuo y la sociedad. Por ello, la conducta o comportamiento de los individuos, en los que la acción de cada uno de ellos está condicionada por las acciones de los demás es, a grandes rasgos, lo que la psicología social intenta establecer como su ámbito de análisis. Es importante apuntar que, desde esta perspectiva, toda interacción o influencia entre sujetos se enmarca en un contexto situacional específico. 


\section{Alejandro George Cruz \\ Los símbolos, la interacción y la estrategia. Una propuesta de abordaje teórico-comunicológico a los fenómenos sociales: el culto a la Santa Muerte como un caso aproximación. Revista Xihmai XIV (27), 35-62, enero-junio 2019}

El inicio de la relación entre psicología social y comunicación se podría ubicar en los estudios de la Escuela de Chicago, que se caracterizó por el esfuerzo de combinar la filosofía pragmática ${ }^{8}$ con un proyecto de ciencia social basada en el empirismo y que desembocó en el desarrollo de una teoría que hacía énfasis en la interacción social y las relaciones interpersonales. De esta manera, surgía el estudio de los fenómenos sociales desde una perspectiva comunicativa, sentando las bases para concebir la comunicación no como una simple transmisión de mensajes, sino como "un proceso simbólico mediante el cual una cultura se erige y se mantiene" (Lazar, 1995, p. 10).

Las aportaciones de esta corriente han sido relevantes para destacar el papel que juega lo simbólico y específicamente el lenguaje como motor de la inteligencia creativa en la resolución de problemas de la acción social. Para la Escuela de Chicago, la interacción es el fenómeno que devela la trama que existe entre lo individual y lo social, convirtiéndose en una fuente de reflexión para comprender la comunicación desde un sentido más originario: el vínculo, la reciprocidad, la comunidad.

\section{La dimensión estratégica de la comunicación}

Ninguna forma de comunicación humana es inocente, es decir, libre de una intencionalidad; siempre ocurre que hay alguien que tiene el propósito de transmitir algo a alguien más con la finalidad de que este último realice algo en respuesta. Es en este sentido que la comunicación humana persigue fines concretos, aunque no siempre queden claros para los participantes en todo acto comunicativo. Cuando dos individuos entran en contacto, en un intercambio dialógico de información, no solo tienen en común el sistema de significación que les permite comunicarse, ni tampoco tienen exclusivamente en común que se afectan mutuamente por dicho intercambio. Ambos deciden iniciar, responder, continuar o mantener dicho intercambio porque obedece a ciertos fines, los cuales pueden ir de lo más convencional a lo más complejo. En este

\footnotetext{
${ }^{8}$ Esta corriente también es conocida como pragmatismo; se trata de una filosofía de la acción que tiene por objetivo la búsqueda cooperativa de la verdad para resolver los problemas que surgen en el transcurso de la acción específicamente «creativa» (Joas, 1998). El pragmatismo surge como una reacción contra el cartesianismo en la obra de Charles Sanders Peirce y Williams James, encontrando su expresión sociológica en los trabajos de John Dewey y George Herbert Mead, representantes de la Escuela de Chicago.
}

Xihmai 52 
Los símbolos, la interacción y la estrategia. Una propuesta de abordaje teórico-comunicológico a los fenómenos sociales: el culto a la Santa Muerte como un caso aproximación.

Revista Xihmai XIV (27), 35-62, enero-junio 2019

intercambio dialógico ambos se "adecuan" mutuamente a responder y actuar conforme la situación lo vaya requiriendo.

Es en este sentido de "adecuación", hecha por los mismos individuos participantes, que la comunicación se plantea, al mismo tiempo, estratégica. Rafael Alberto Pérez (2014) destaca tres grandes paradigmas para comprender el término estrategia: el militar, el matemático/científico y el económico/managerial.

Con relación al paradigma militar, se puede decir que es entre los siglos $\mathrm{V}$ y VI a. C. se tienen los primeros términos de la palabra estrategia en ámbitos militares para expresar la acción de dirigir. Es hasta inicios del siglo XX que se rompe con este paradigma y se trasladan los principios estratégicos a conflictos sociales sin la violencia de la guerra bajo los factores de: persecución de objetivos en situaciones competitivas, participación de actores y la posibilidad de elección.

El paradigma matemático de la estrategia surgió en la Universidad de Princeton, en la década de los cuarenta del siglo XX, bajo los auspicios de la "Teoría de Juegos". Uno de los principales elementos de esta teoría es el de la toma de decisiones (conflictivas/competitivas). Una decisión solo es estratégica cuando, en el cálculo que hace el decisor, para elegir entre una u otra alternativa de acción, tiene en cuenta la eventual participación de otros agentes que pueden ser personas, fuerzas o sistemas que con su intervención pueden modificar el resultado.

El paradigma económico/managerial centra su atención en el campo de la administración y los negocios, en los que los indicadores cuantitativos, jerárquicos, matriciales y racionalistas ocupan un lugar preponderante para la toma de decisiones.

Según el mismo Pérez (2014), la comunicación permite la mediación en la interacción entre los diversos participantes, adecuando y ajustando las expectativas que se tienen en relación con el acto social que los convoca, en contextos particulares, considerando la totalidad de los actores que entran en juego tanto directa como indirectamente. 


\section{Alejandro George Cruz \\ Los símbolos, la interacción y la estrategia. Una propuesta de abordaje teórico-comunicológico a los fenómenos sociales: el culto a la Santa Muerte como un caso aproximación. \\ Revista Xihmai XIV (27), 35-62, enero-junio 2019}

Es necesario reconocer que, en lo relacionado a esta dimensión, hay todavía mucho por indagar e integrar a los estudios de comunicación, pues el propio campo disciplinar se encuentra en una constante renovación de su objeto de estudio.

\section{Una propuesta de aproximación conceptual desde la comunicación al fenómeno del culto a la Santa Muerte}

Esta aproximación se plantea desde una mirada exploratoria, si bien no hay una hipótesis de trabajo, lo que se pretende evidenciar es que la perspectiva de la comunicación puede aportar un entendimiento que enriquezca la visión antropológica y sociológica. Lo anterior puede ayudar a comprender que el culto, como forma de acción social, contextualizada en escenarios de la vida cotidiana, está imbricada en procesos de comunicación en los que existen símbolos, interacciones y fines.

Como parte del proyecto de investigación para la materia de Análisis de datos, referida al inicio de este texto, se organizó una visita a la Iglesia de la Santa Muerte, ubicada en la calle 8 Oriente, No. 415, en la Colonia Centro de la ciudad de Puebla, Puebla, México. Se determinó utilizar la técnica de observación para registrar lo sucedido durante esta visita, se planteó la estrategia de incursión al campo, toma de registro fotográfico y realización de notas inmediatamente después de salir del campo. A continuación se presenta una reconstrucción de esta visita, tomando como base los registros de observación de los participantes.

\section{Descripción de la ubicación física y del lugar}

Al acercarse al lugar se nota un portón grande, de inicio pareciera ser la entrada de un negocio como cualquier otro en el Centro, ya que se observan estanterías que exhiben gafas de sol, de diversas formas y tamaños, las cuales se encontraban en venta. Una vez cerca de la entrada, se pueden apreciar en las estanterías un gran número de velas, figuras de la Santa Muerte y algunos frasquitos de colores, los cuales llevan etiquetas. Frente a la estantería se ubica un altar en honor a la Santa Muerte. El altar se compone de estatuillas de diversos tamaños, una tenía vestimenta verde mientras que la otra portaba una indumentaria dorada. La segunda entrada conduce al templo de la Santa

Xihmai 54 


\section{Alejandro George Cruz \\ Los símbolos, la interacción y la estrategia. Una propuesta de abordaje teórico-comunicológico a los fenómenos sociales: el culto a la Santa Muerte como un caso aproximación. \\ Revista Xihmai XIV (27), 35-62, enero-junio 2019}

Muerte, la entrada es pequeña, los colores que predominan sobre las paredes son el blanco y el morado. El lugar está poco iluminado; en las paredes se encuentran imágenes de la Santa Muerte cuya indumentaria es azul, en su mano se aprecia una esfera azul que simboliza el mundo. También se aprecia una Santa Muerte de color rojo, pero esta se encuentra junto a un árbol. Las figuras e imágenes que se aprecian son la Virgen de Juquila, San Judas Tadeo, Ángeles que parecen ser de la mitología griega, el Niño Dios, un Cristo y la Virgen María. El lugar no parece una Iglesia en cuanto a la estructura, pareciera que fue una casa hace tiempo. Al igual que en las iglesias católicas, hay reclinatorios, bancas y un altar principal, donde la figura que se encuentra en el centro es Cristo. Junto a Cristo se encuentran dos figuras grandes de la Santa Muerte, una tiene un vestido blanco, la otra un manto dorado; debajo de las figuras se encuentra la ofrenda que sus devotos le obsequian, como un refresco de marca Coca-Cola, hojas de mariguana y cigarros.

\section{Descripción de hechos relevantes sucedidos durante la observación}

El primer hombre que entró en la iglesia se hincó en los reclinatorios y permaneció ahí durante un largo rato, haciendo sus peticiones. Cuando culminó sus oraciones salió a la recepción y regresó con una veladora en mano que encendió y colocó en el altar que contenía la imagen más grande de la Muerte, ataviada de color blanco; posteriormente, se dirigió a una habitación contigua y de ahí salió con un ramo de rosas rojas. Procedió a distribuirlas entre los floreros de los altares laterales. Cerca de uno de estos altares se encontraba sentada una de las estudiantes del curso, que participaba en el ejercicio de trabajo de campo; el hombre en cuestión se aproximó a ella y le extendió con su mano derecha una rosa, la cual fue aceptada. Posteriormente, la estudiante refirió que ese acto le dejó una impresión muy fuerte que le duró todo aquel fin de semana, ya que el hecho de aceptarla y dejarla posteriormente en unos de los altares, para no llevársela a su casa, le incomodó, pues sentía que había participado sin querer de una ofrenda presentada a la Santa Muerte.

El segundo hombre al entrar se detuvo en la primera estatua de la Santa Muerte que estaba en la entrada de la iglesia; tiene un tamaño mediano; después de mirarla fijamente por minutos, procedió a tocarla y acariciar la estatua para después persignarse. Antes de irse, caminó hasta el altar principal y comenzó 
Los símbolos, la interacción y la estrategia. Una propuesta de abordaje teórico-comunicológico a los fenómenos sociales: el culto a la Santa Muerte como un caso aproximación.

Revista Xihmai XIV (27), 35-62, enero-junio 2019

a tocar el vestido blanco de la imagen de la Santa Muerte que se ubicaba en la parte delantera del templo. Cabe destacar que esta porta una indumentaria de color blanco, más exactamente un vestido de novia, con velo y adornos en forma de flores. El hombre que se ubicó al frente de ella frotó su rostro contra el vestido y posteriormente sacó una cartera del bolsillo trasero de su pantalón, el cual también frotó con la indumentaria de novia que portaba la estatua.

\section{Descripción de las personas}

Durante el tiempo que se realizó la activad en la iglesia, se pudo observar a dos personas de sexo masculino quienes, por sus características físicas, se puede suponer que tenían edades de entre treinta y cuarenta años. Uno de ellos se encontraba con pantalón de vestir y una playera azul, fajada, y cinturón; su cabello de color castaño llegaba hasta sus hombros.

El segundo hombre que se adentró en la iglesia estaba vestido con pantalón de mezclilla, chamarra muy grande color verde y zapatos igualmente grandes. $\mathrm{Su}$ cabello presentaba un corte similar al que portan policías o militares.

\section{Algunas consideraciones sobre el ejercicio de observación y la codificación de la información}

Cabe recordar que este reporte de observación es el resultado de un ejercicio llevado a cabo por estudiantes de licenciatura con el objetivo de familiarizarlos con la técnica y suscitar en ellos una reflexión de su proceso de observación teniendo como perspectivas teóricas los símbolos, la interacción y la estrategia, es decir, una mirada comunicológica.

Si bien este reporte de observación no sería muy diferente de los que se hacen con una perspectiva antropológica o sociológica, la diferencia estriba en la forma de percibir y codificar la información, teniendo como base de clasificación las dimensiones comunicacionales descritas. A continuación, se presenta un cuadro que intenta una clasificación de los elementos observados durante esta actividad de campo y que se han distribuido teniendo como base las dimensiones anteriormente abordadas:

Xihmai 56 
Los símbolos, la interacción y la estrategia. Una propuesta de abordaje teórico-comunicológico a los fenómenos sociales: el culto a la Santa Muerte como un caso aproximación.

Revista Xihmai XIV (27), 35-62, enero-junio 2019

\begin{tabular}{|l|l|l|}
\hline \multicolumn{1}{|c|}{$\begin{array}{c}\text { Dimensión } \\
\text { simbólica }\end{array}$} & \multicolumn{1}{c|}{$\begin{array}{c}\text { Dimensión } \\
\text { Interaccional }\end{array}$} & \multicolumn{1}{c|}{$\begin{array}{c}\text { Dimensión } \\
\text { Estratégica }\end{array}$} \\
\hline $\begin{array}{l}\text { Formas y } \\
\text { tamaños }\end{array}$ & $\begin{array}{l}\text { Obsequios u ofrendas } \\
\text { a la imagen }\end{array}$ & ¿Por qué ofrendan? \\
\hline Colores & Rezos & ¿Por qué rezan? \\
\hline $\begin{array}{l}\text { Imágenes } \\
\text { religiosas }\end{array}$ & $\begin{array}{l}\text { Gesticulaciones como } \\
\text { el acto de santiguar }\end{array}$ & ¿Por qué gesticulan? \\
\hline $\begin{array}{l}\text { Indumentarias y } \\
\text { accesorios }\end{array}$ & $\begin{array}{l}\text { Frotamientos y } \\
\text { caricias }\end{array}$ & $\begin{array}{l}\text { ¿Por qué realizan } \\
\text { estos actos? }\end{array}$ \\
\hline Altares & $\begin{array}{l}\text { Ofrecimiento entre } \\
\text { creyentes }\end{array}$ & $\begin{array}{l}\text { ¿Por qué buscan la } \\
\text { interacción con otros } \\
\text { fieles? }\end{array}$ \\
\hline Flores & & \\
\hline Veladoras & & \\
\hline
\end{tabular}

\section{Cuadro 1. Elaboración Propia.}

El cuadro anterior refleja la forma lógica en que los elementos observados durante el ejercicio se han clasificado para identificarlos y diferenciarlos de tal manera que, desde el punto de vista de los participantes, se ubican en alguna de las dimensiones comunicológicas.

A modo de un primer intento de interpretación de los elementos identificados y diferenciados, podríamos decir que la comunicación es un proceso social básico que nos hace seres sociales. La sociedad misma podría considerarse como un entramado de signos y significaciones que surgen de las interacciones humanas. Como afirma John B. Thompson (1998), "los seres humanos no sólo producen y reciben expresiones lingüísticas significativas, sino que también dan significado a construcciones no lingüísticas: acciones, obras de arte, y objetos materiales de diversos tipos".

Los significados que adquieren las formas, los tamaños, los colores, las indumentarias, en el contexto del culto a la Santa Muerte, no son azarosos, son parte de un sistema de significación que ha sido configurado con el tiempo y en contextos sociales específicos, cuyos significados y significantes se han socializado y compartido entre los devotos. Esta socialización es aprendida de otros, compartida por otros, que a través de las interacciones logran difundir los signos y sus 
Los símbolos, la interacción y la estrategia. Una propuesta de abordaje teórico-comunicológico a los fenómenos sociales: el culto a la Santa Muerte como un caso aproximación.

Revista Xihmai XIV (27), 35-62, enero-junio 2019

significaciones en conversaciones, rituales, gesticulaciones, ofrecimientos.

Cabe señalar que la incursión en el campo no produjo la información suficiente como para lograr una codificación en la dimensión de la estrategia, pero sí permite plantear algunos interrogantes que podrían abordarse en entregas posteriores de este proyecto de investigación que, una vez realizado este escrito, se ha puesto en marcha nuevamente.

\section{FUENTES de CONSUlta}

ALlPORT, F. (1968). Social Psychology. Cambridge, United Kingdom: Hounghton Mifflin.

BERGER, P. y Luckmann, Th. (2001). La construcción social de la realidad. Buenos Aires, Argentina: Amorrortu Editores.

BLASCO, J., Grimaltos, T. y Sánchez, D. (1999). Signo y pensamiento. Filosofía. Barcelona, España: Ariel.

DUMMET, M. (1973). Frege. Philosophy of Language, Cambridge, United States of America: Harvard University Press.

ECO, U. (1988). Signo. Barcelona, España: Lumen.

FLORES MARTOS, J. (2014). Iconografías emergentes y muertes patrimonializadas en América Latina: Santa muerte, muertos milagrosos y muertos adoptados. AIBR. Revista de Antropología Iberoamericana, 9 (2), 115-140.

GARCÍA-CARPINTERO, M. (1996). Las palabras, las ideas y las cosas. Una presentación de la filosofía del lenguaje. Filosofía. Barcelona, España: Ariel.

GAYTÁN ALCALÁ, F. (2008). Santa entre los Malditos: Culto a La Santa Muerte en el México del siglo XXI. LiminaR, 6, 1, 40-51. Recuperado el 31 de octubre de 2018 de http://www.scielo.org.mx/scielo.php?script=sci_arttext\&pid=S1665$80272008000100004 \& \operatorname{lng}=\mathrm{es} \& \ln \mathrm{ln}=\mathrm{es}$

Xihmai 58 
HARTLEY, E. y Hartley, R. (1986). La importancia y naturaleza de la comunicación. En R. Peredo (Comp.). Introducción al estudio de la comunicación (pp. 21-38). Serie Iberoamericana de comunicación. Ciudad de México, México: Universidad Iberoamericana.

HUSSERL, E. (1942). Meditaciones Cartesianas. Ciudad de México, México: El Colegio de México.

HUSSERL, E. (1954). Invitación a la fenomenología. Barcelona, España: Paidós.

JOAS, H. (1998). El pragmatismo y la teoría de la sociedad. Madrid, España: CIS/Siglo XXI.

LAZAR, J. (1995). La ciencia de la comunicación. Ciudad de México, México: Publicaciones Cruz.

LEIBNIZ, G. W. (1977). Nuevos ensayos sobre el entendimiento humano. Madrid, España: Editora Nacional.

LOCKE, J. (1956). Ensayo sobre el entendimiento humano. Ciudad de México: FCE.

LÓPEZ, F. (1997). La ciencia de la comunicación, método y objeto de estudio. Ciudad de México, México: Trillas.

MARTINO, L. (2001). Elementos para una epistemología de la comunicación. En Fuentes, R. e Immacolata, M. (Comps.). Comunicación. Campo y objeto de estudio. Perspectivas reflexivas latinoamericanas (pp. 7590). Ciudad de México, México: ITESO / UDG.

MEAD, G. H. (1972). Espíritu, persona y sociedad. Barcelona, España: Paidós.

O’SULLIVAN, T., et.al. (1997). Conceptos claves en comunicación y estudios culturales. Buenos Aires, Argentina: Amorrortu Editores.

PAYRATÓ, Ll. (1998). De profesión lingüista. Panorama de la lingüística aplicada. Prácticum. Barcelona, España: Ariel. 
Los símbolos, la interacción y la estrategia. Una propuesta de abordaje teórico-comunicológico a los fenómenos sociales: el culto a la Santa Muerte como un caso aproximación.

Revista Xihmai XIV (27), 35-62, enero-junio 2019

PEIRCE, Ch. (1986). La ciencia de la semiótica. Buenos Aires, Argentina: Nueva Visión.

PEIRCE, Ch. (1987). Obra lógico-semiótica. Madrid, España: Taurus Comunicación.

PERDIGÓN CASTAÑEDA, J. K. (2015). La indumentaria para La Santa Muerte. Cuicuilco, 22 (64), 43-62. Recuperado el 31 de octubre de 2018 de http://www.scielo.org.mx/scielo.php?script=sci_arttext\&pid=S0185$16592015000300003 \& \operatorname{lng}=$ es\&tlng=es.

PÉREZ. R. A. (2014). La estrategia como campo de estudio. ¿Tenemos ya un nuevo paradigma? Revista Mediterránea de Comunicación, 5 (2), 931. doi: https://doi.org/10.14198/MEDCOM2014.5.2.03

REYES RUIZ, C. (2011). Historia y actualidad del culto a la Santa Muerte. El Cotidiano. Revista de la realidad mexicana actual, (169), 51-57.

RIZO, M. (2005). La Psicología Social y la Sociología Fenomenológica. Apuntes teóricos para la exploración de la dimensión comunicológica de la interacción, 2 (3). Recuperado de http://gmje.mty.itesm.mx/articulos3/articulo_4.html

RODA, F. y Beltrán, R. (1988). Información y comunicación. Los medios y su aplicación didáctica. Barcelona, España: Gustavo Gili.

SALOMON, G. (1981). Communication and education. Beverly Hills, United States of America: Sage Publication.

SAUSSURE, F. de. (1998). Curso de lingüística general. Ciudad de México, México: Fontamara.

SCHÜTZ. A. (1993). La construcción significativa del mundo social. Barcelona, España: Paidós.

WATSON, J. B. (1972). El conductismo. Buenos Aires, Argentina: Paidós.

WEBER, M. (1984). Economía y sociedad. Esbozo de sociología comprensiva. Ciudad de México, México: FCE.

Xihmai 60 
Alejandro George Cruz Los símbolos, la interacción y la estrategia. Una propuesta de abordaje teórico-comunicológico a los fenómenos sociales: el culto a la Santa Muerte como un caso aproximación. Revista Xihmai XIV (27), 35-62, enero-junio 2019

WITTGENSTEIN, L. (1987). Tractatus Logico-Philosophicus. Madrid, España: Alianza Editorial.

VITALE, A. (2002). El estudio de los signos. Peirce y Saussure. Buenos Aires, Argentina: EUDEBA. 
Alejandro George Cruz

Los símbolos, la interacción y la estrategia. Una propuesta de abordaje teórico-comunicológico a los fenómenos sociales: el culto a la Santa Muerte como un caso aproximación. Revista Xihmai XIV (27), 35-62, enero-junio 2019

Xihmai 62 